Brandon, S. (1969). British Medical fournal, 4, 557.

B.M.A. Working Party (1968). British Medical fournal, 4, 572

Campbell, D. B. (1971). South African Medical fournal, Supplement 45, 10 Dement, W., and Greenberg, S. (1966). Electroencephalography and Clinical Neurophysiology, 20,523.

Elderton, W. P. (1938). Frequency Curves and Correlation. Cambridge, Cambridge University Press.

Fain, J. N., Kovacev, V. P., and Scow, R. O. (1965). Fournal of Biological Chemistry, 240, 3522 .

Gagnon, M. A., Tétreault, L., and Bordeleau, J. M. (1969). Activitas Nervosa Superior, 11, 202

Haider, I., and Oswald, I. (1970). British Medical fournal, 2, 318.

Hunter, W. M. (1968). In Growth and Development of Mammals, ed. G. A. Lodge and G. E. Lamming. London, Butterworths. Lewis, S. A. (1970). In Amphetamines and Related Compounds, ed. E. Costa
and S. Garattini. New York, Raven Press.

Lewis, S. A., and Oswald, I. (1969). British fournal of Psychiatry, 115, 1403.
Lewis, S. A., Oswald, I., Evans, J. I., Akindele, M. O., and Tompsett, S. L. (1970). Electroencephalography and Clinical Neurophysiology, 28, 374. oswald, I. (1970). In Amphetamines and Related Compounds, ed. E. Costa and S. Garattini. New York, Raven Press.

Oswald, I., Jones, H. S., and Mannerheim, J. E. (1968). British Medical

Fournal, 1, 796.
Oswald, I., Lewis, S. A., Dunleavy, D. L. F., Brezinova, V., and Briggs, M. (1971). British Medical fournal, 3, 70.

Oswald, I., and Thacore, V. R. (1963). British Medical fournal, 2, 427.

Rechtschaffen, A., and Kales, A. (editors). (1968). A Manual of Standardized Terminology, Techniques and Scoring System for Sleep Stages of Human Subjects. Washington, D.C., U.S. Government Printing Office.

Riley, I., Corson, J., Haider, I., and Oswald, I. (1969). Lancet, 2, 1162.

Sassin, J. F., et al. (1969a). Science, 165, 513.

Sassin, J. F., et al. (1969b). Life Sciences, part I, 8, 1299.

Williams, R. L., Agnew, H. W., and Webb, W. B. (1964). Electroencephalography and Clinical Neurophysiology, 17, 376.

\title{
Drugs of Dependence Though Not of Abuse: Fenfluramine and Imipramine
}

\section{Summary}

Measures of subjective feeling used by five patients indicated that depression of mood occurred about four days after fenfluramine withdrawal. An experiment in which another 11 patients took fenfluramine $80 \mathrm{mg}$ for 28 days confirmed the depression, maximal on the fourth withdrawal day. It also indicated that in the first week of administration there was some mood elevation, but with feelings of impaired ability to concentrate. The drug reduced appetite and weight. A comparison is drawn with imipramine, which was found to induce initial and withdrawal changes of subjective experience (of dreaming) in six volunteers. It is suggested that certain mood-influencing drugs may not be drugs of abuse because of some unpleasant initial effects, though they can be drugs of dependence.

\section{Introduction}

A few years ago amphetamine was not accepted as a drug of addiction because "physical" withdrawal features were supposedly absent. Nevertheless, clinicians encountered amphetamine addicts and observed inertia, sleepiness, and depression of mood following withdrawal. The brain is a "physical" organ and governs psychological function, and as techniques become mos ;ophisticated withdrawal signs after more drugs must be discovered. They may be traditionally physical or, since brain physiology dic es mental life, of a psychological nature. Today we have drug "abuse" and drug "dependence" (W.H.O., 1969). The former implies use of a drug contrary to law or

\footnotetext{
Department of Psychiatry of the University of Edinburgh, Royal Edinburgh Hospital, Edinburgh EH10 5HF

IAN OSWALD, M.D., D.P.M., Reader in Psychiatry S. A. LEWIS, B.SC., PH.D., Research Psychologist Di. L. F. DUNLEA BREZINOVA, M.D., PH.D., Research Psychiatrist MAASTA BREZINOVA, M.D., PH.D., Research
}

medical opinion. Dependence implies that the drug influences behaviour and that through repeated experience the organism is in some way changed, so that if the drug is stopped it is then missed and withdrawal features appear. Like other brain responses dependence could be expected to be a graded and not an absolute phenomenon.

We have found that regular intake of fenfluramine, an amphetamine derivative, leads to dependence on the drug for the maintenance of normal mood, and, for comparison, we show a minor form of dependence on imipramine.

\section{Measuring Instruments}

A drug may influence how a man feels. Observers can make inferences about how he feels and attempt measurement, but a man's inner, subjective experience is his alone, and he alone can truly describe it. Words are often inadequate, so we used a simple thermometer-like measure, a line, $10 \mathrm{~cm}$ long, on which the patient could make a mark to indicate where, along a continuum of feeling, he would place himself that day. The number of $\mathrm{mm}$ along the line was eventually measured. Visualanalogue self-rating scales of this type have been discussed by Aitken (1969).

The principal measuring device was a sheet of paper with space for name and date and a $10-\mathrm{cm}$ line running across it with, at the left-hand end, the words, "Most depressed ever," and at the right-hand end, "most cheerful ever." The instructions were: "Please indicate by a mark on the line how you felt in your spirits today. If you have felt more lively and cheery than usual you should make your mark to the right of centre, if more listless and gloomy than usual your mark should be to the left. An average day should mean a mark in the centre." It was completed at night and the measures from it are taken as measures of mood.

Similar 10-cm lines were used to measure appetite. They were marked "no appetitite at all" at one end, and at the other end "greatest ever relish for food." Patients were reminded that there is a difference between relish for food and amount eaten. Another sheet of paper gave a self-estimate of how well the patient had felt able to concentrate mentally and ran from "extremely difficult to concentrate" to "wonderfully alert and penetrating mind." A morning sheet gave a self-estimate of dreaming and ran from "absolutely dreamless in retrospect" to "seemed to be vivid dreaming all the time." 


\section{Fenfluramine: First Experiment}

Five men of varying degrees of obesity participated in a laboratory study of the effect of fenfluramine on their sleep (Lewis et al., 1971) and completed the mood self-rating each time they attended the laboratory. Periods of blank tablets (placebos), then of fenfluramine tablets, and of blank tablets again, followed one another over the course of months. Four men who had received fenfluramine $80 \mathrm{mg} /$ day had mood scores that all fell in withdrawal. In one man (Case 1) this fall, to far below his previous other scores, was for only one day, the fourth since the last fenfluramine. In the others self-reported depression lasted longer, as Fig. 1 shows, but was worst three to five days after withdrawal.
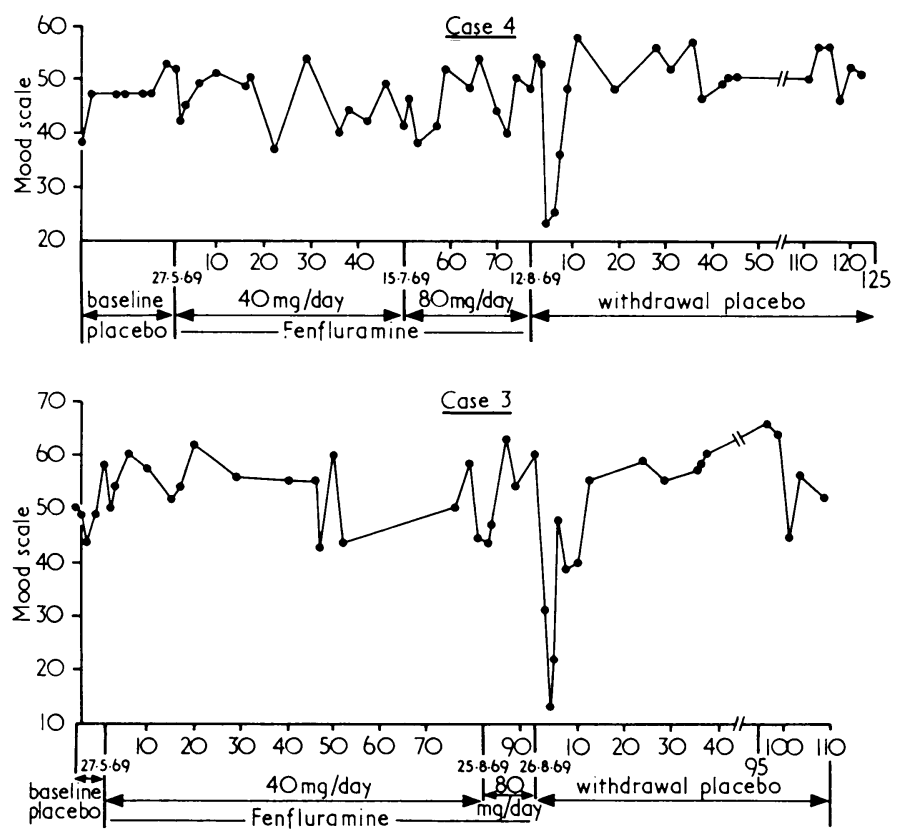

FIG. 1-After taking fenfluramine for 78 and 94 days respectively these two patients, when marking their self-rating mood scales, indicated that they felt depressed in the week after fenfluramine withdrawal.

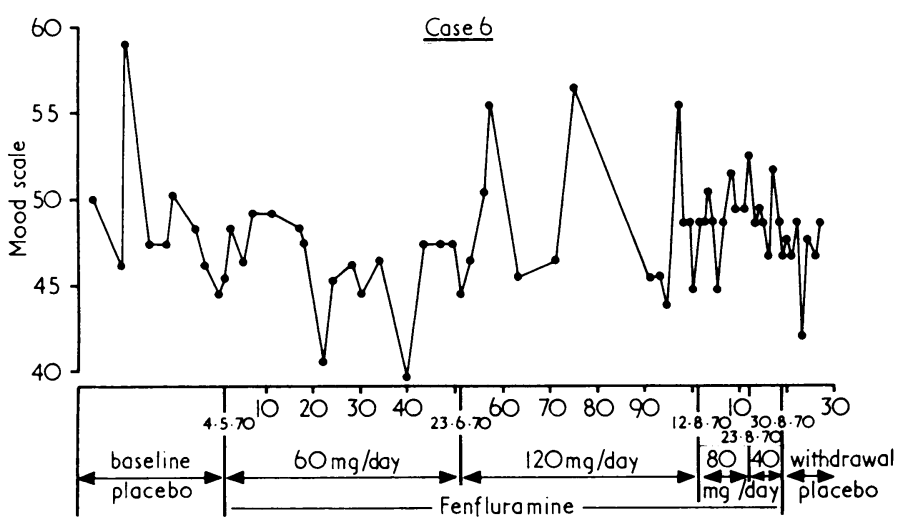

FIG. 2- When this patient was asked to make a daily self-rating of his mood the range of his scores appeared to narrow (right-hand side of graph). His fenfluramine was withdrawn in steps, but despite this he indicated a sharp drop on the fourth day after finally stopping the drug, when his absolute score was the lowest for three months.

Patients create their own scale and range of measures, and these can shift as time passes. Fig. 2 refers to a $111-\mathrm{kg}$ man who received up to $120 \mathrm{mg}$ of fenfluramine per day. Late in the study we asked him to complete his rating scale, not just on laboratory nights but on every evening, and it can be seen that his range narrowed. Dosage was reduced in steps, but even so, four days after withdrawal he marked his mood scale to indicate a greater degree of depression than he had done for the preceding three months.

\section{Fenfluramine: Second Experiment}

The first experiment led us to conduct a similar study with 11 patients who took fenfluramine for 28 days, and to predict that they would reveal depression of mood, maximal on the fourth withdrawal day.

Six women and five men aged 20-53 who wished to lose weight were asked to participate. None were grossly obese, and in a different era of fashions possibly none of the women would have wished to slim. They received individual day packs of four tablets. The length of the initial blank-tablet period was deliberately varied from 7 to 13 days, and the final blanktablet period between 9 and 13 days. They started on different week-days so that in the case of the women their expected menses should fall about the middle of the 28 days on fenfluramine $80 \mathrm{mg} /$ day. Two tablets were taken before breakfast and two before the evening meal. Each evening they rated their mood, appetite, and concentration for the day. All had first been screened for a clear bill of mental health, personal and family. They were able to consult us if they wished, but we saw them for general inquiries only just before starting blank tablets, in the middle of the fenfluramine month, after 10 post-withdrawal days, and at the end.

\section{Results}

We first examined the data in a way that took account of the patients' personal scales and ranges of subjective-feeling scores, examining ratios between a patient's own score for one day and that for his other days. All had at least seven baseline scores. The mean of these seven was found for the individual and then the deviation of each day's score from this personal baseline mean was determined. This was done for all 11 patients. The 11 personal deviations for each day were summed and divided by 11 to give a mean deviation for each baseline day. The standard deviation (S.D. or $\sigma$ ) of the baseline scores was obtained for each patient and the group S.D. for the same scores according to the formula,

$$
\text { group S.D. }=\sqrt{\overline{\Sigma\left(\mathrm{Nj} \sigma \mathrm{j}^{2}\right.}}
$$

where $\mathrm{N}=$ number of observations, $\mathfrak{j}=$ subscript denoting which patient, and $J=$ number of patients. The mean deviations were similarly found for each fenfluramine day and for

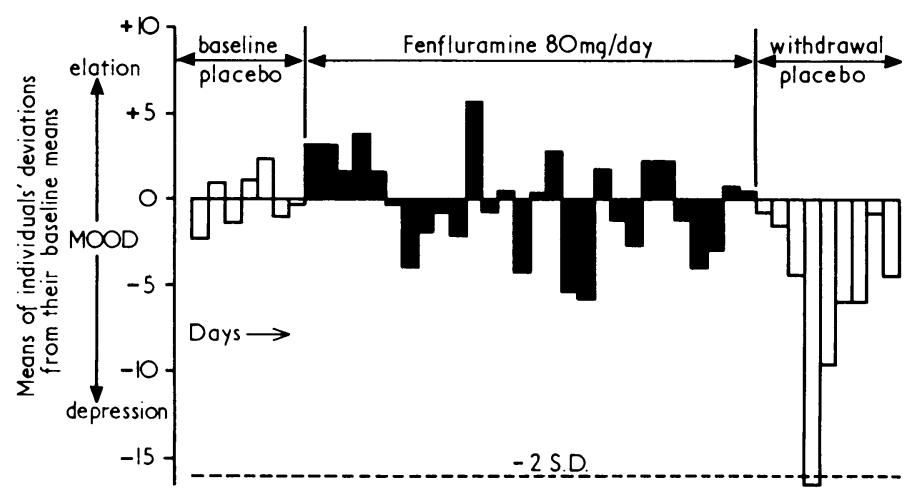

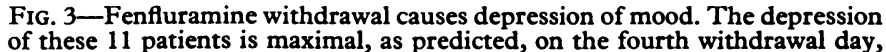
of these 11 patients is maximal, as predicted, on the fourth withdrawal day,
and on that day is more than 2 S.D. below baseline. They had become and on that day is more than 2 S.D. below baseline.
dependent on the drug for maintenance of normal mood. 
each withdrawal day, by again using individual deviations from personal baseline means.

Mood scores fell after drug withdrawal and the patients indicated their most severe depression on the fourth day of withdrawal (Fig. 3). Since the most extreme deviation from the mean was on the predicted day among the 44 , and in the predicted direction, the probability of the result arising by chance could be 1 in 88 , but since that deviation exceeded 2 S.D. from the baseline mean, the likelihood that chance could be responsible is even more remote.

In the first experiment mood scores were started in case elevation might occur with fenfluramine. No obvious elevaton was observed, but in the second experiment higher mood scores clustered just after the start of fenfluramine. To smooth out transients, five-point moving means of raw scores, averaged across patients for each day, have been used to prepare Fig. 4 (thus days 1-5 were averaged to give the mean for day three, days 2-6 gave the mean for day 4 , and so on). In Fig. 4 the highest point of mood elevation among the 40 possible occurs at the third day of drug administration and the low point at days 5 and 6 after withdrawal (Fig. 3 shows skew during withdrawal).

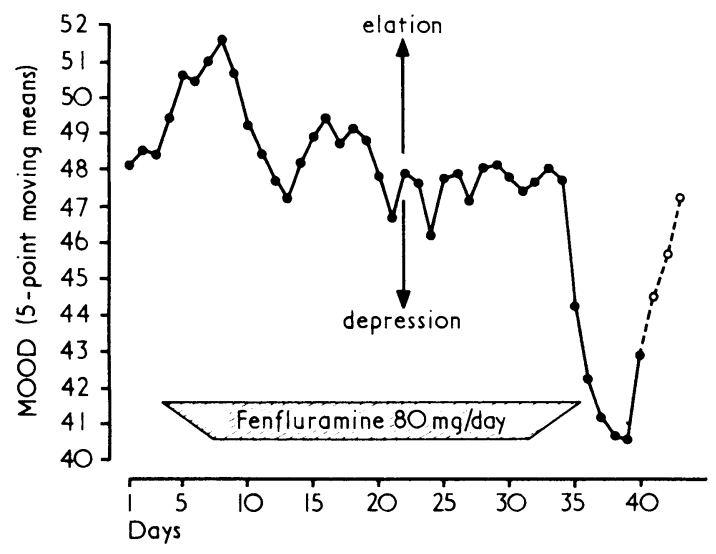
Fig. 4- When fenfluramine is first started patients tend to rate themselves
as slightly elevated in mood, as well as depressed after withdrawal. The last as slightly elevated in mood, as well as depressed after withdrawal. The last
three values are based on only 10,9 , and 8 patients respectively, owing to three values are based on only 10,9 , and 8 patients respectively, owing to
the staggered end of the study. The moving-mean technique causes both drug and drug-free days to contribute to certain points on the graph, as indicated by the trapezium.

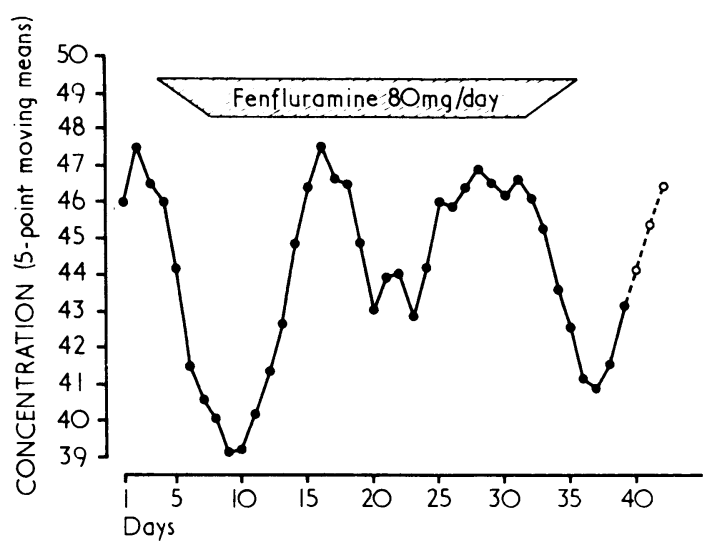

FIG. 5-Fenfluramine causes feelings of impaired mental powers when first given, and again during the eventual withdrawal period of mood depression. The last three values are based on 10,9 , and 8 patients only.

Patients were not requested to write comments on their rating sheets but did so, especially during the withdrawal period when phrases included, "feeling depressed," "extremely light-headed, drowsy, and depressed (for no reason) today," "a feeling of uneasiness," "unwell," "anxious," "tense," "a tightness which I felt throughout my body," "very tired and out of sorts," "very upsetting dreams," "headache," "palpitations," "irritable," "narky," and "may be starting a cold."

A 40-year-old man scored himself lower on the fourth withdrawal day than any previous day but went lower still until the ninth. When seen on the tenth day he spoke of having "been weeping all week-end," to the alarm of his family. He recovered in the next few days.

The self-rating scores for concentration and for appetite on no day reached 2 S.D. from the baseline after the manner of Fig. 3, but five-point moving means show subjectively impaired concentration in the first week on the drug and in the withdrawal period (Fig. 5). There was a self-rated decrease of appetite while on the drug (Fig. 6), with lowest score on the tenth day and, interestingly, an upward acceleration from a week after drug withdrawal-as one man then wrote, "very hungry, eating sweets, most unusual for me." Mean weight loss over the whole period was $3.0 \mathrm{~kg}(P<0.02)$.

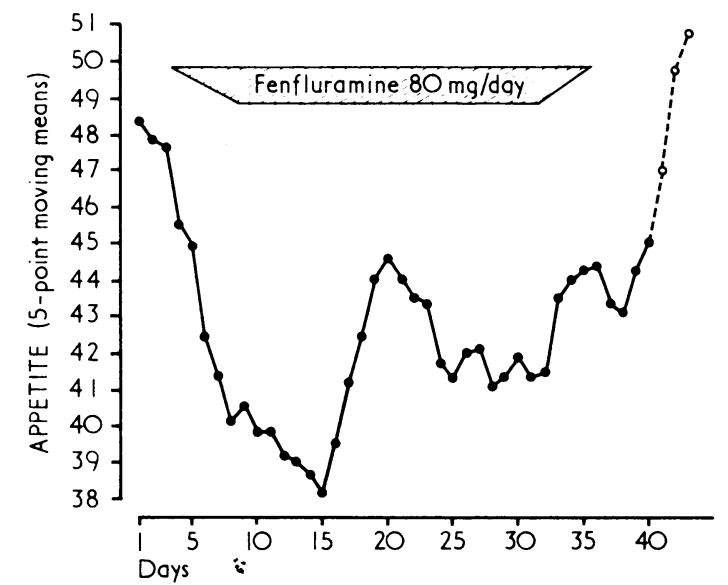

FIG. 6-Fenfluramine diminishes appetite, but a delayed increase of appetite seems to follow withdrawal. The last three values are based on only 10,9 , and 8 patients, however.

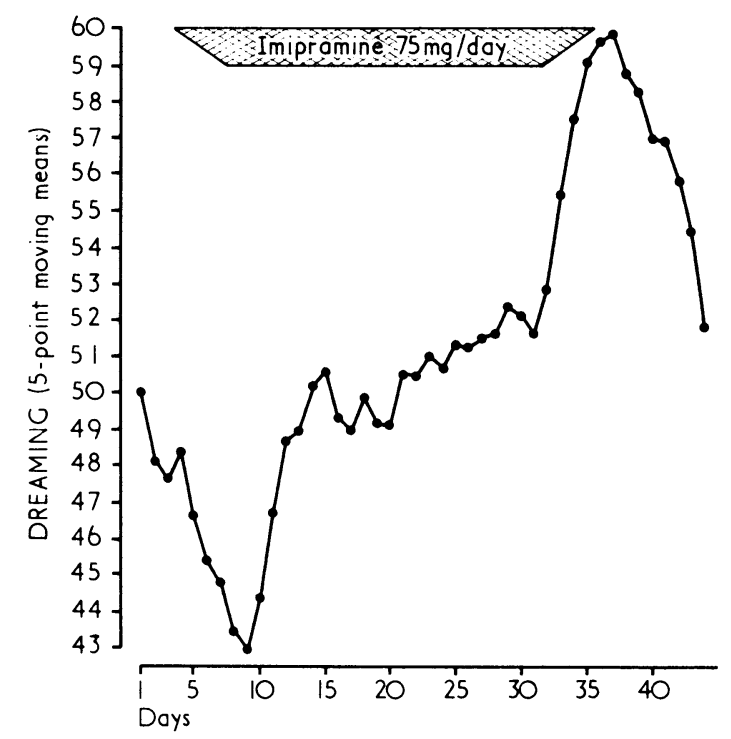

FIG. 7-Imipramine at first causes a subjective impression of reduced dreaming, but eventual withdrawal of the drug is followed by a subjectively great increase of dreaming. They had become dependent on the drug for maintenance of normal dreaming. 


\section{Imipramine Experiment}

Six healthy male volunteers undertook dream self-rating for 48 successive mornings. They had taken 3 tablets at 9 p.m. each previous day, receiving 7 days of blanks, 28 days of imipramine $75 \mathrm{mg}$, and then 13 days of blanks. The five-point moving means are shown in Fig. 7 and indicate subjective diminution of dreaming when first on the drug, and an increase to a peak after the fourth withdrawal night. Examination of the data by the method used for Fig. 3 showed a rise to more than 2 S.D. above the baseline mean on withdrawal nights $1,2,3,4,6$, and 8.

\section{Discussion}

Fenfluramine is a drug that alters the brain concentrations of noradrenaline and dopamine (Ziance and Kinnard, 1967) and of serotonin (Duhault and Verdavainne, 1967) and might be expected to influence mood. It is an amphetamine derivative widely prescribed in Britain yet it has not shown abuse potential. Young drug-takers in London seem not to choose fenfluramine, according to Hawks (1970), of the Addiction Research Unit, Institute of Psychiatry (confirmed by personal communication, Hawks, 1971). Amphetamine addicts do not credit fenfluramine with effects qualitatively similar to those of amphetamine (Götestam and Gunne, 1971). Isolated reports of young persons who have experimented with fenfluramine above the recommended dose indicate that their experiences were unpleasant (Brandon, 1969; Riley et al., 1969).

Imipramine is used as a mood-altering drug, but there is nothing to suggest that it is a drug of abuse. Yet electrophysiological techniques can demonstrate withdrawal abnormalities after imipramine, maximal after about four days and lasting a month (Dunleavy, Brezinova, Oswald, MacLean, and Tinker, to be published) and Fig. 7 suggests withdrawal abnormalities of subjective experience that most people would think of as unpleasant.

Fenfluramine, though also not taken for pep at parties, caused withdrawal abnormalities of subjective experience (Figs. 1, 2, 3 , and 4) that were certainly unpleasant, with a severity of depression sufficient to cause us concern in the case of one man. The nadir was reached after four days without the drug, and we suspect that this delay accounts for there being only one other report that recognizes depression as a consequence of fenfluramine withdrawal (Golding, 1970). The four-day delay parallels the delay to a peak of withdrawal abnormality in cerebral electrophysiology (Lewis et al., 1971) and may be attributed to the slow elimination of the drug, for which three to four days are needed (Campbell, 1971). Gradual reduction of dose of fenfluramine would seem clinically important, though may not wholly prevent depression (Fig. 2).

In the measures of subjective experience, and in electrophysiological measures (Lewis et al., 1971), some initial effects of fenfluramine decreased with time. When tolerance occurs and a drug "loses its effect" it is not the drug that is changed but the brain, and sometimes the liver. We would suppose that internal monitoring devices detect departures from normal brain physiology and lead to the creation of neuronal modifications that counteract the drug. If the drug is stopped the modifications, now unrestrained by the drug, couse the withdrawal abnormalities, opposite in kind to the drug's actions, and do so until such time as the turnover of neuronal components, and perhaps shorter-term adjusting mechanisms, lead to restoration of normality. Obviously subjective powers of concentration can be impaired either directly by a drug or by withdrawal depression and anxiety (Fig. 5).

We believe that drugs such as imipramine and fenfluramine cause a number of differing initial subjective effects, some of which are unpleasant. The feeling of impaired mental powers after fenfluramine contrasts with feelings of enhanced mental powers often described with amphetamine. If unpleasant initial effects of a drug outweigh initial pleasant effects, and if elimination is slow and so prevents a rapid "let-down," the drug's abuse potential might be expected to be low.

Finally, we would emphasize that the techniques we have used could probably show unwanted subjective effects, both of administration and withdrawal, with many other drugs, including other slimming pills.

The research received unwavering support from Servier Laboratories Ltd. We are indebted to the Scottish Hospital Endowments Research Trust and the Scottish Home and Health Department for other finance.

\section{References}

Aitken, R. C. B. (1969). Proceedings of the Royal Society of Medicine, 62, 989.

Brandon, S. (1969). British Medical fournal, 4, 557.

Campbell, D. B. (1971). South African Medical fournal, Supplement 45, 10

Duhault, J., and Verdavainne, C. (1967). Archives Internationales de Pharmacodynamie et de Therapie, $170,276$.

macodynamie et de Therapie, 170, 276.
Golding, D. (1970). British Medical fournal, $1,238$.

Gotestam, K. G., and Gunne, L. M. (1971). South African Medical Fournal, Supplement, 45, 32.

Hawks, D. V. (1970). British Medical fournal, 1, 238

Lewis, S. A., Oswald, I., and Dunleavy, D. L. F. (1971). British Medical fournal, 3,67 .

Riley, I., Corson, J., Haider, I., and Oswald, I. (1969). Lancet, 2, 1162

W.H.O.'(1969). Technical Report Series, No. 407.

Ziance, R., and Kinnard, W. J. (1967). Pharmacologist, 9, 244. 